\title{
Investigation of Microgrid Hierarchical Control and Structure
}

\author{
Tayebeh Faghihi ${ }^{1}$, Shahab Sabzi ${ }^{2 *}$ \\ ${ }^{1}$ Department of Electrical Engineering, University of Isfahan, Isfahan 8415683111, Iran \\ ${ }^{2}$ Department of Electrical Engineering, Arak University of Technology, Arak 3818146763, Iran
}

Corresponding Author Email: Shahab.sabzi@gmail.com

https://doi.org/10.18280/ama_c.751-401

Received: 20 July 2020

Accepted: 15 November 2020

\section{Keywords:}

microgrid, control systems, distribution network, battery, renewable energy, smart city, smart grid

\begin{abstract}
This paper offers a literature review on different structures and control strategies of the microgrid. The implementation of a microgrid system provides significant advantages for both electric utility and end-users. Microgrid control is one of the most sophisticated parts of such implementations that must be taken into account before moving to the next steps. The different control objectives and structures of the main grid and microgrid lead to various control methods proposed for microgrids. The hierarchical structure is the most accepted method for microgrid control that has three levels including primary, secondary, and tertiary. The focus of this study will be on the main modes of typical microgrids, types of microgrid and how to control them. The investigation of this paper will give an overview to the readers, and in our next paper, we will focus more deeply on the subject, with a specific concentration on the concept of secondary control and corresponding trending methods.
\end{abstract}

\section{INTRODUCTION}

The ever-increasing global warming and environmental pollution resulting from the utilization of fossil fuels has lifted the application of renewable energy sources [1]. On the other hand, in the traditional power networks where long transmission lines connected the power grid supply to the consumer's location did not prove to be economical. This network arrangement results in electrical energy losses on far distances and also threatens the network stability. The distribution network that is fed only through the transmission networks is unstable, and also there is the risk of blackout. Therefore, distributed generation units (DG) were introduced to meet the consumer demands on remote locations [2]. Consequently, the concept of "microgrid" has been announced in the literature and industry that can be defined as an automatic low voltage generation and distribution grid consisting of loads, DGs, and controllers, in which power losses are significantly decreased because of DGs proximity to the consumer's location. On the other hand, distributed generation provides higher reliability, because if one DG is removed for any reason, another one can take its place [3].

The microgrid includes a set of DGs, energy storage systems (ESS), loads, and demand-side management (DSM).

There are two operational Modes in microgrids [4]:

- Connected mode

- $\quad$ Islanded mode

In the connected mode, the microgrid is connected to the grid via point of common coupling (PCC) by which, the main grid regulates voltage and frequency, and in islanded mode, microgrid operates as an independent entity and is responsible for regulating the voltage, frequency, and powersharing; provided via proper control methods.

The best way to put the DG units in a unified form is by using a hierarchy control method and energy management units [5]. Microgrid has many advantages for consumers and electric power companies. From the consumer's point of view, a microgrid can increase network reliability, improve the power quality, and reduce the cost of power consumption. From the perspective of distribution companies, employing microgrid leads to declining consumer demand and thus reduction of the construction of transmission lines and facilities. Also, because of eliminating peak points, losses are lowered $[6,7]$.

Moreover, microgrids provide local voltage and frequency regulation support and improve the reliability and power capacity of the grid [8-10]. However, the development of microgrid has challenges that must be considered, such as operation, control, security, and stability [11].

Due to the uncertain nature of some DERs such as wind turbines, and solar panels, their frequency, and output power are unpredicted, and therefore proper interfaces, and adequate controllers must be used regarding them. A power electronic converter and the corresponding controller can be used to control the active and reactive powers, responding to the changes of the load and providing quick and flexible voltage and frequency control. Thus, converter control is another crucial parameter that must be taken into account by the microgrid operator [12].

In order to control the microgrid, many structures have been presented. In this paper, microgrid control structures with a focus on hierarchical control are presented. As mentioned, hierarchical control is one of the most usual methods of microgrid control, consisting of primary, secondary, and tertiary stages. The primary level consists of internal control loops for active and reactive power-sharing. Secondary level eliminates initial steady-state error that is caused by primary control. Also, secondary control determines voltage and frequency operating set points in islanded mode. Therefore, it can restore and synchronize 
microgrid with the main grid. Reliable operation of the system, ensuring power quality, distortion reduction of frequency and voltage and economic performance of microgrid are other functions of secondary control. Tertiary level handles the economic issues, microgrid participation in the electricity market and energy exchange between the microgrid and the main grid.

In this paper, first, a review on the microgrid different operational modes and structures is presented in section II, and then in section III, the hierarchical levels of microgrid control are analyzed and in the end, conclusions, and some proposals or future research are proposed in section IV.

\section{MICROGRID STRUCTURE}

As mentioned above, a microgrid consists of DGs, loads, energy storage systems, controller, energy management system (EMS), and demand-side management system. microsources are divided into two categories, micro sources such as micro-turbines and fuel cells with constant output power, and wind turbines, and photovoltaic with variable power depending on ambient conditions [13]. The general structure of microgrid is shown in Figure 1.

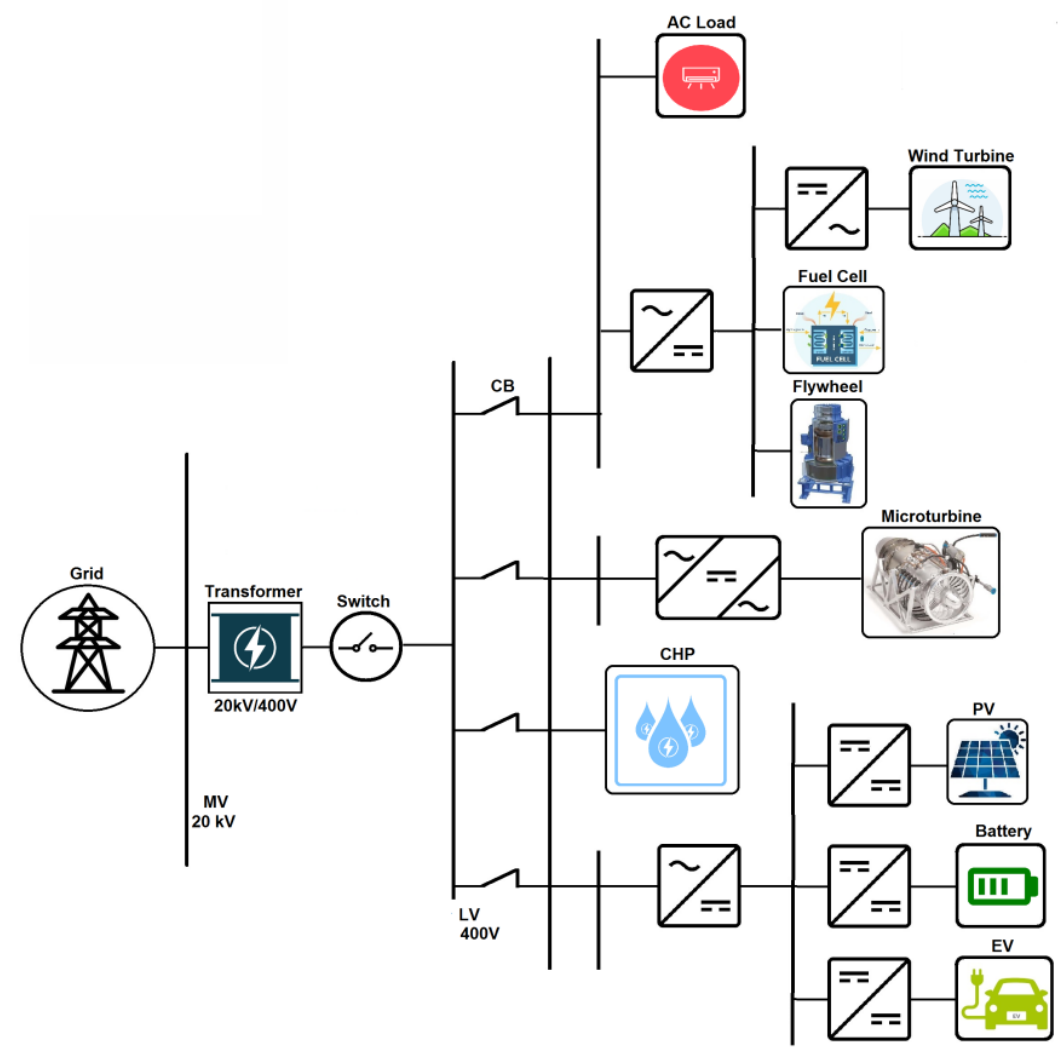

Figure 1. The general structure of a microgrid

Among the merits of microgrids, improving reliability, reducing losses by reducing the distance between generation and consumption locations, reducing emissions, operation improvement, and long-term investment issues, power quality improvement, declining the power outages, and maintenance simplicity can be mentioned. However, there are many challenges in developing microgrids. Some of these challenges are [14]:

Quality control issues. In this way, the deviation of voltage and frequency can be eliminated by adequate secondary control.

Creation of interference in reclosing the islanded microgrid to the distribution network that needs appropriate synchronization and control loops. If there is a difference between the voltage phase of main grid and microgrid, controllers must prevent re-joining them.

The high price of distributed generation resources.

There are safety and protection issues in resolving errors that may not be detected by the systems inside microgrid. So, necessary protective measures should be considered.

The market monopoly that would not allow active participation of microgrid in the electricity market.
In order to control the microgrid and overcome the mentioned challenges, it is essential to determine the operational mode. For this purpose, microgrid operation modes are introduced and discussed. In any case, control objectives and microgrid functions should be identified.

\subsection{Microgrid operational modes}

As mentioned, the microgrid can operate in two main modes; connected to the main grid and islanded mode. In a normal situation, the microgrid connects to the main grid and supplies the loads. A microgrid may need to be disconnected from the main grid under certain circumstances in which microgrid is an independent entity that operates in islanded mode, and supplies loads uninterruptedly. These two operational modes will be explained more specifically in the following sections.

\section{Grid-connected mode}

In connected mode, the voltage level of point of common coupling (PCC) is determined by the main grid, and the central role of the microgrid is matching the active/reactive 
power generated by the DGs with the load. Reactive power injected by a DG unit can be used for power factor correction, reactive power supply, or voltage control at the corresponding connection point.

According to current standards, DG units with limited generation capacity will not be able to support grid equipment for frequency and voltage settings. On the other side, power equipment may not be allowed for regulating voltage or to be controlled by DG units in connected mode [15].

\section{Islanded mode}

A microgrid can be isolated from the main grid, and still supply the consumers with reliable power. It can also feed the loads independently. A microgrid must be separated from the main grid under the following conditions:

Predefined islanded operation: If any error such as public events or long-term voltage drop occurs in the main grid or main grid needs to be repaired, microgrid should operate in islanded mode.

Non-predefined islanded operation: when there is a blackout by disconnecting from the main grid, microgrids should be able to support loads using the appropriate algorithms.

Once microgrid operates in islanded mode, DG units are responsible for the feeding system and stability of rated voltage and frequency while power-sharing between generation units is organized [16]. Also, DG units must prevent an overload of the inverters. In islanded mode, microgrid must solve the following issues:

Frequency and voltage adjustment: system acts as a voltage source and ensures the power flow; the frequency and voltage control loops are set within the permissible range.

Balance the supply and demand: in islanded mode, the variations in frequency are followed by the new operating point for active power, which leads to changes in the power angle between the grid and microgrid. In these circumstances, the microgrid should be able to meet the demand.

Power Quality: a high-power quality can be achieved at two levels. At first, the reactive power and harmonic current are measured, and in the second stage, reactive power and harmonic compensation are carried out. Thus, the microgrid can meet the power quality requirements of the main grid.

Also, in the islanded mode, all DG units are considered fixed power sources that inject arbitrary power to the grid [17, $18]$.

When the power supply outage occurs, or an error in the main grid is detected, the microgrid is isolated from the main grid, and the recovery process commences and continues until the system ensures that the desired reliability has already been achieved. In this case, power reference should again be placed at a nominal value. Besides, if the maximum permissible deviation does not exceed a permissible value for frequency and voltage. When the microgrid operates in islanded mode and the main grid is prone to an error, stability and synchronizing voltage and frequency should be achieved while connecting to the grid. The recovery process is performed to synchronize the system frequency and power generation in the main grid. During this stage, balancing between active and reactive power, and coordination of DG units are important [18].

Inverters are essential requirements for connecting microgrid to the main grid. Structures of inverters for AC and DC sources are shown in Figures 2 and 3 [19].

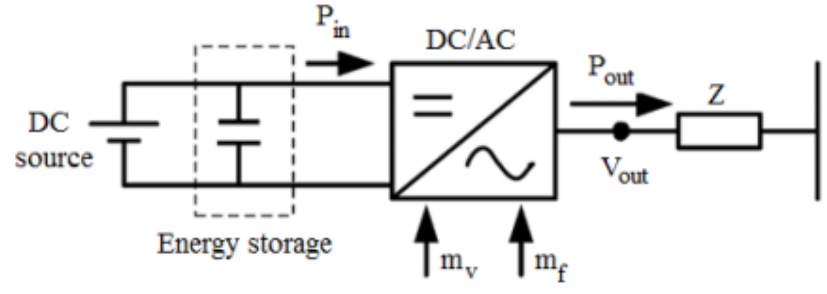

Figure 2. Inverters for DC distributed resources [19]

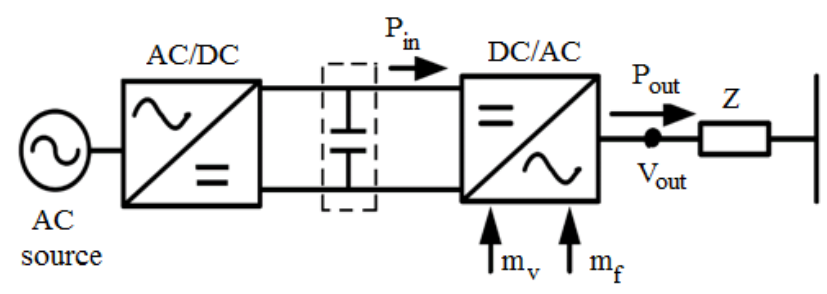

Figure 3. Inverters for AC distributed resources [19]

\subsection{Classification of microgrids}

Microgrids can be categorized based on the types of the generation power and converters used, to three types of $\mathrm{AC}$, DC, hybrid. Each of these kinds has a specific purpose and structure [20]. These types and their applications are discussed in the following section.

\section{$\underline{\text { AC Microgrids }}$}

An AC microgrid system connected to a medium voltage network is shown in Figure 4(a). The main system includes $\mathrm{AC}$ or DC sides, DG units, and energy storage systems that are connected in some parts of the distribution network [21]. The microgrid is connected to the system through an AC low voltage line at PCC and supplies AC loads directly and DC loads using DC/AC converters. AC microgrid systems, including wind turbines, wave, and biogas, may need $\mathrm{AC} / \mathrm{DC} / \mathrm{AC}$ converters.

In AC microgrids, control is performed to stabilize the voltage, synchronize the inverter frequency with rated value, power-sharing (active and reactive) between the inverters concerning their capacity and provide additional services for the main grid. The control of AC microgrid uses a voltage regulator and a reactive power regulator. Voltage regulators are responsible for adjusting voltage through the microgrid, and the reactive power regulators manage reactive powersharing concerning the impedance of the transmission line [22].

\section{$\underline{\text { DC microgrids }}$}

DC microgrid includes photovoltaic arrays, fuel cells, and energy storage systems (batteries and supercapacitors) [2325]. The microgrid is connected to the grid at PCC via lowvoltage DC line, supplies DC loads directly, and AC loads using DC/AC converters [20-22].

In order to supply sensitive loads, a DC/AC converter is required. The main advantages of the microgrid are loss reduction, load security, efficiency improvement, no need for regulations in frequency, phase, reactive power, and power quality control, no need to synchronize the DGs when connecting to a DC link and lack of blackout's impact on DC microgrids. Besides these, the main challenge for microgrid development is protection issues. It is possible to connect the batteries and capacitors directly to the DC bus (but using 
converters is preferred) and flywheel should connect to the DC link through a converter [26]. The main objectives of the DC microgrid control are DC voltage regulation in nominal value, current (power) sharing between the converters, and performing load flow [21]. DC microgrids are depicted in Figure 4(b).

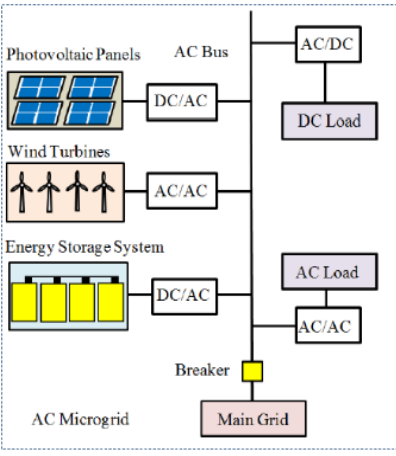

(a)

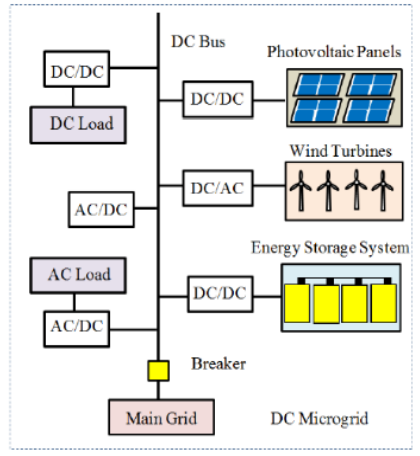

(b)
Figure 4. (a) AC microgrid, (b) DC microgrid [27]

\section{Hybrid microgrids}

$\mathrm{DC}$ and $\mathrm{AC}$ microgrids are the critical elements for incorporating DGs as distributed energy storage systems [12]. A hybrid microgrid is a combination of DC and AC microgrids that provides better connectivity for different distributed generation units. This microgrid can be used in both grid-connected and islanded mode, and its generation capacity is equal to total power generated by $\mathrm{DC}$ and $\mathrm{AC}$ microgrids. In this type of microgrids, $\mathrm{AC} / \mathrm{DC}$ and $\mathrm{DC} / \mathrm{AC}$ converters must be used simultaneously [28, 29]. A hybrid microgrid is shown in Figure 5.

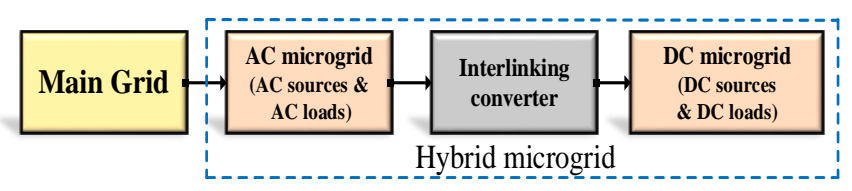

Figure 5 Hybrid microgrid

Table 1. AC and DC microgrids comparison in different modes

\begin{tabular}{|c|c|c|}
\hline Mode & AC Microgrid & DC Microgrid \\
\hline $\begin{array}{l}\text { Grid- } \\
\text { connected }\end{array}$ & $\begin{array}{l}\text {-Provides control } \\
\text { methods: prediction, } \\
\text { security, power flow. } \\
\text {-Maintains synchronized } \\
\text { operation. }\end{array}$ & $\begin{array}{l}\text {-Controls the power } \\
\text { flow demand and } \\
\text { voltage variation } \\
\text { under changed } \\
\text { conditions and loads } \\
\text {-Scheduling, load } \\
\text { profile, and demand- } \\
\text { side management }\end{array}$ \\
\hline Islanded & $\begin{array}{l}\text {-Active and reactive } \\
\text { power control, voltage } \\
\text { profile, frequency control } \\
\text { with the help of the } \\
\text { energy storage system. } \\
\text {-Maintain reliability of } \\
\text { power supply and } \\
\text { interconnects the } \\
\text { microgrid with the utility } \\
\text { grid after clearance of } \\
\text { fault. }\end{array}$ & $\begin{array}{l}\text {-Controls and maintain } \\
\text { power flow and load } \\
\text { voltage during any } \\
\text { disturbance. } \\
\text {-Stabilizes the } \\
\text { generated voltage. }\end{array}$ \\
\hline
\end{tabular}

AC and DC microgrid functions in two operational modes are summarized in Table 1. Various protection and control functions are explained.

Structure, operating modes, and types of a microgrid are discussed. In order to implement the microgrid and achieve to listed advantages, appropriate control systems are required. In the next section, microgrid control will be investigated to realize stable and reliable operation.

\section{MICROGRID CONTROL}

The main control variables of a microgrid are frequency, voltage, and active/reactive power [30]. In the connected mode, the microgrid frequency and voltage operating points are determined by the main grid. In this case, the main role of microgrid control is to match the active/reactive power generated by DG units and loads. In islanded mode, microgrid acts as an independent entity and there would be more challenges than the connected mode. Microgrid voltage and frequency are not supported by the main grid and therefore must be controlled by DER units. Microgrid control is implemented mainly based on voltage and frequency as the main parameters, and various structures will be provided for this purpose [31].

Microgrid control should support and control microgrid activities with high security in both islanded and gridconnected modes. When microgrid is disconnected from the main grid, the control system must control local voltage level and frequency. It should calculate the difference between generation and consumption of active/reactive power on the island origin and do necessary steps for grid stability. The control system also has other functions such as maintaining microgrid against failures, errors, and outages and setting consumers in its most optimal modes [6, 32].

In general, the microgrid controller must meet the following objectives [33]:

1. Operation of micro-sources in the permissible range (primary and secondary control in both operational modes).

2. Active and reactive power-sharing (primary and secondary control in grid-connected mode).

3. Seamless connections and disconnection from the main grid (primary control in both operational modes).

4. Participation in a market with the optimization of local micro-source and power exchange with the grid (tertiary control in islanded mode).

5. Uninterruptible supply of sensitive loads such as medical equipment and computer servers (in both operational modes).

6. Working through a black start operation in case of any general error (in islanded mode).

7. Increasing the system's performance and reliability by providing support from the energy storage systems (primary and secondary control in both operational modes).

In terms of implementation, microgrid control can be divided into two categories, centralized and decentralized. Each one is used depending on the microgrid type, grid conditions, and control level. In recent studies, among the various control structures, hierarchical control has been the most widely used method, which is implemented in centralized and decentralized structures. Hierarchical control has three control levels including primary, secondary, and tertiary. 

[31]:

Microgrid control must have the following characteristics

Output control: voltages and currents of DER units must track their reference values, and oscillations must be damped completely (primary and secondary control in both operational modes).

Power balancing: DG units in microgrids should be able to correct sudden imbalances in active power and keep the deviations of frequency and voltage in an acceptable range (primary and secondary control in both operational modes).

Demand Side Management (DSM): appropriate DSM methods should be designed to control the load (tertiary control in both operational modes).

Economic dispatch: proper dispatch of DG units in microgrid reduces operating costs and increases total profit (primary, secondary and tertiary control in islanded mode).

As mentioned, microgrid control can be implemented in the form of centralized and decentralized. In a centralized structure, hierarchical control levels can be classified as follows [34-36]:

1. Local controllers, including micro-source controllers (MC) and local controllers (LC).

2. Microgrid central controller (MGCC).

3. Distribution Management System (DMS).

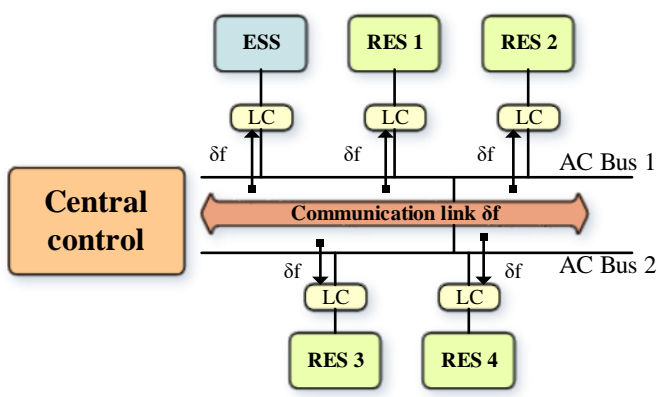

(a)

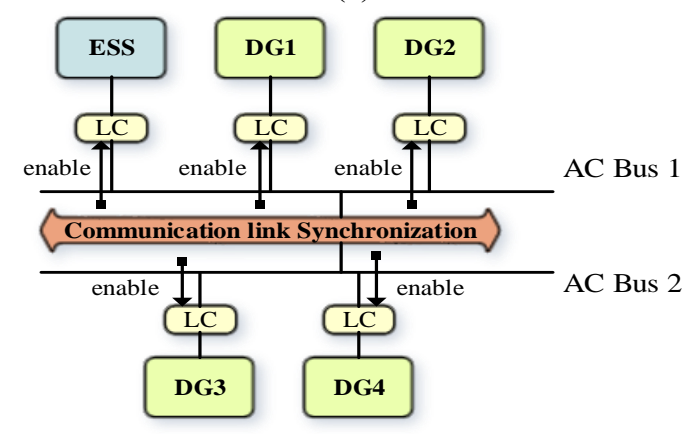

(b)

Figure 6. Structure of microgrid control: (a) centralized structure and (b) decentralized structure [32]

The local controller manages the operating point of microsources and related power electronics interfaces without utilizing communication systems. So, it has a simpler circuit and requires a lower cost. In this level, measurements are local voltages and currents $[33,37]$. In centralized control, local control is installed in the location of controllable loads and is usually used for demand-side management [38].

There is one MGCC for each microgrid that is the interface between the grid and the DMS. MGCC plays different roles including coordination of local controllers and optimization of microgrid performance. The difference between the centralized and decentralized control is determined by defined tasks for the MGCC and tasks divided between MGCC, MC, and LC. In the centralized control, MC and LC perform the MGCC commands in grid-connected mode, and in islanded mode, decision-making is performed by $\mathrm{MC}$ and LC [38].

MGCC includes several vital functions (such as economic management and control functions) and manages the hierarchical control system. At the secondary level of hierarchical control, local controllers are located on-site of loads, and micro-source controllers exchange information with the central controller. In this case, MGCC is responsible for the microgrid performance by setting the operating point of the MC and LC [39]. LC is used as an interface for controllable loads through local load shedding in emergencies and $\mathrm{MC}$ controls active and reactive power generation levels of the micro-sources. The exchanged information between network controllers includes basic commands such as the operating points of active and reactive powers and voltage level information of LC and MC [40].

Distribution Management System or distribution network operator consists of several central control units and is responsible for low voltage and medium voltage zone management. Decentralized control in microgrids is performed to make the right decisions locally for microsource planning in different situations. The decentralized control responsibilities are given to the $\mathrm{MC}$ to perform the operations of maximum generation and covering of the demands, in order to reduce the market price. In this case, local controllers and micro-source controllers only exchange information with their neighbors. Structures of centralized and decentralized controllers are shown in Figure 6.

In centralized and decentralized controllers, coordinated and sustainable system function depends on the frequency synchronization between DGs and energy storage systems through the communication link.

\subsection{Hierarchical Structure}

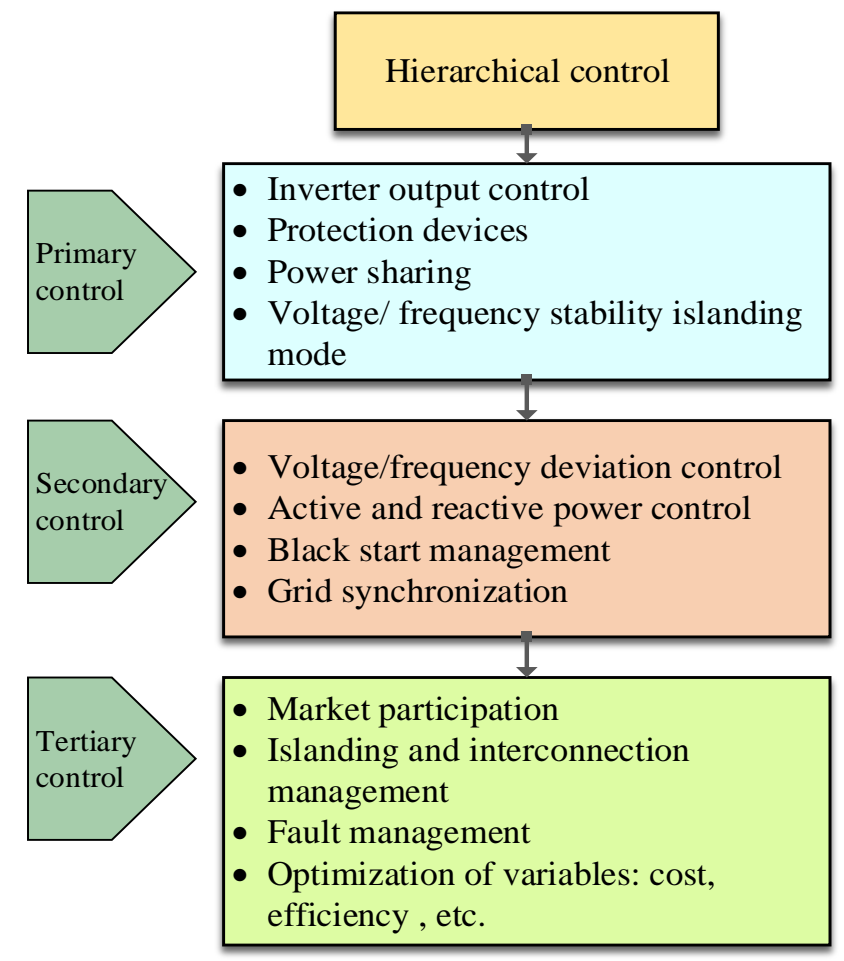

Figure 7. Microgrid hierarchical control 
In large-scale power systems, multi-level hierarchical control has become a well-known method, and it has been used progressively in recent years. Therefore, hierarchical control must be defined under standards such as those for large power systems in order to perform the adequate operation of microgrids. The primary, secondary and tertiary controls are presented as the three essential levels of control loops in the microgrid. These levels differ in terms of response rate, operational time frame and requiring infrastructures such as communications systems [41, 42]. Figure 7 shows the hierarchical structure of microgrids.

\subsection{Primary control}

Droop control is usually implemented at the primary level, and there is one droop based outer power loop for each inverter, namely automatic or decentralized control. The aim of this level is active and reactive power sharing between DG units and improving system performance, stability and frequency, and voltage regulation. The following equations express the droop control scheme.

$$
\begin{aligned}
& \omega=\omega^{*}-m\left(P-P^{*}\right) \\
& E=E^{*}-n\left(Q-Q^{*}\right)
\end{aligned}
$$

where, $Q^{*}, E^{*}$ are frequency and voltage amplitudes of the operating point, $m, n$ are specified coefficients corresponding to the operating slopes, and $P^{*}, Q^{*}$ are the active/reactive power references, respectively. In this way, frequency and voltage outputs are determined by using the local active/reactive power of each unit and sharing $P / Q$ [43]. Primary control has the fastest responses in comparison with the secondary and tertiary control levels; mainly utilized the conventional linear control methods and can be implemented based on the measurement of local signals [41].

\subsection{Secondary control}

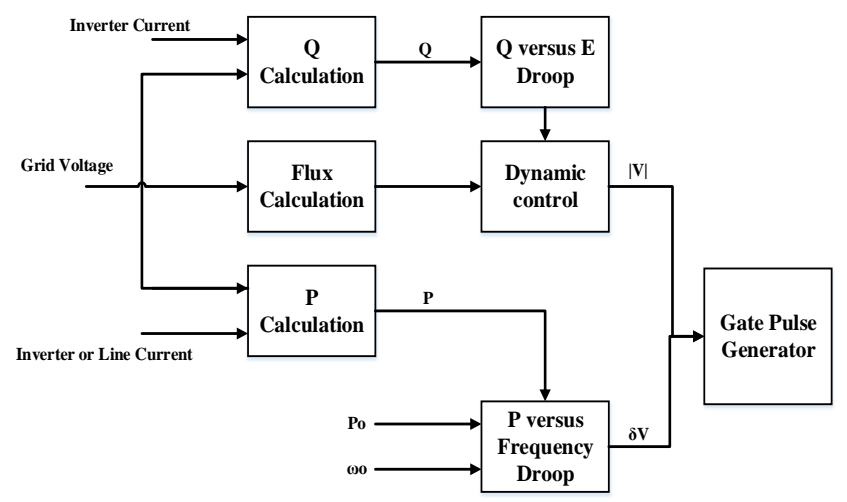

Figure 8. The primary droop control structure

As illustrated in Figure 8, the main task of secondary control is voltage and frequency restoration and synchronization [44]. In order to restore the microgrid voltage to the nominal value, a system must send corresponding signals to primary control with the deployment of low bandwidth communication. Also, this control can be used to synchronize the microgrid with the main grid between the islanded and grid-connected modes. The secondary control must be able to measure the deviation amplitudes of voltage and frequency and send the required reference values for the droop characteristics of each DG unit [18].

\subsection{Tertiary control}

In the third loop of hierarchical control, setting the reference of grid-connected inverter and maximum power point tracking is performed to optimize the energy-sharing operation. The operating points of microgrid inverters are adjusted such that a control power flow in general (microgrid energy input and output) or local sectors (energy hierarchical or consumption) can be realized. Usually, power flow depends on economic issues. Economic data should be processed and used for decision-making in the microgrid. Each controller should be automatically responded to system changes without requiring control information. For example, $P^{*}$ can be set to a positive or negative value to inject or absorb active power, and $Q^{*}$ is set to zero to achieve a unity power factor. Frequency and voltage reference and saturated value of them with the permissible maximum and minimum within a microgrid will be sent to the secondary control. By applying this level of control, additional functions such as islanded tracking or the grid voltage harmonic reduction are achieved by injecting harmonics. As a result, the microgrid can be fully controlled using hierarchical methods [18].

\section{CONCLUSION}

In this paper, microgrid structures and control methods were reviewed. Also, microgrids were introduced and investigated briefly divided into three types of $\mathrm{AC}, \mathrm{DC}$, and hybrid. In section III, the essential sections of three hierarchical levels of control were analyzed, and the role of each one in the corresponding operation was highlighted.

It was also shown that secondary control plays an important role in the hierarchical structure; therefore, in our next paper, we will focus deeply on the secondary controller, and a vast literature review will be conducted.

\section{REFERENCES}

[1] Rinaldi, G., Menon, P.P., Edwards, C., Ferrara, A. (2020). Higher order sliding mode observers in power grids with traditional and renewable sources. IEEE Control Syst. Lett., 4(1): 223-228. https://doi.org/10.1109/LCSYS.2019.2923605

[2] Sordiashie, E., Moayedi, S., Alahmad, A., Polese, L., Alahmad, M. (2019). Harvesting from ambient energy: Designing enabling technologies for sustainable buildings. 2019 IEEE International Conference on Electro Information Technology (EIT), Brookings, SD, USA, pp. 69-78. https://doi.org/10.1109/EIT.2019.8834323

[3] Jahid, A., Monju, M.K.H., Hossain, M.E., Hossain, M.F. (2018). Renewable energy assisted cost aware sustainable off-grid base stations with energy cooperation. IEEE Access, 6: 60900-60920. https://doi.org/10.1109/ACCESS.2018.2874131

[4] Che, L., Khodayar, M., Shahidehpour, M. (2013). Only connect: Microgrids for distribution system restoration. IEEE Power and Energy Magazine, 12(1): 70-81. 
https://doi.org/10.1109/MPE.2013.2286317

[5] Ashabani, S.M., Mohamed, Y.A.R.I. (2014). New family of microgrid control and management strategies in smart distribution grids-Analysis, comparison and testing. IEEE Trans. Power Syst., 29(5): 2257-2269. https://doi.org/10.1109/TPWRS.2014.2306016

[6] Balaguer, I.J., Lei, Q., Yang, S.T., Supatti, U., Peng, F.Z. (2011). Control for grid-connected and intentional islanding operations of distributed power generation. IEEE Trans. Ind. Electron., 58(1): 147-157. https://doi.org/10.1109/TIE.2010.2049709

[7] Yu, X.H., Cecati, C., Dillon, T., Simões, M.G. (2011). The new frontier of smart grids. IEEE Ind. Electron. Mag., 5(3): 49-63. https://doi.org/10.1109/MIE.2011.942176

[8] Llaria, A., Curea, O., Jiménez, J., Camblong, H. (2011). Survey on microgrids: Unplanned islanding and related inverter control techniques. Renew. Energy, 36(8): 2052-2061.

https://doi.org/10.1016/j.renene.2011.01.010

[9] Bae, I.S., Kim, J.O. (2008). Reliability evaluation of customers in a microgrid. IEEE Trans. Power Syst., 23(3):

1416-1422. https://doi.org/10.1109/TPWRS.2008.926710

[10] Patrao, I., Figueres, E., Garcerá, G., González-Medina, R. (2015). Microgrid architectures for low voltage distributed generation, Renew. Sustain. Energy Rev., 43: 415-424. https://doi.org/10.1016/j.rser.2014.11.054

[11] Sabzi, S., Asadi, M., Moghbelli, H. (2016). Design and analysis of Lyapunov function based controller for DCDC boost converter. Indian J. Sci. Technol., 9(48): 1-6. https://doi.org/10.17485/ijst/2016/v9i48/97561

[12] Guerrero, J.M., Vasquez, J.C., Matas, J., de Vicuña, L.G., Castilla, M. (2011). Hierarchical control of droopcontrolled AC and DC microgrids-A general approach toward standardization. IEEE Trans. Ind. Electron., 58(1): 158-172. https://doi.org/10.1109/TIE.2010.2066534

[13] Kamel, R.M., Chaouachi, A., Nagasaka, K. (2011). Enhancement of micro-grid performance during islanding mode using storage batteries and new fuzzy logic pitch angle controller. Energy Convers. Manag., 52(5):

2204-2216. https://doi.org/10.1016/j.enconman.2010.12.025

[14] Chowdhury, S., Chowdhury, S.P., Crossley, P. (2009). Microgrids and Active Distribution Networks. IET Renewable Energy Series 6, the Institution of Engineering and Technology, London, United Kingdom. https://doi.org/10.1049/PBRN006E

[15] IEEE Standard for Interconnecting Distributed Resources with Electric Power Systems. (2013). IEEE Std 1547-2003, pp. 1-28.

[16] Katiraei, F., Iravani, M.R., Lehn, P.W. (2005). Microgrid autonomous operation during and subsequent to islanding process. IEEE Trans Power, 20(1): 248-257. https://doi.org/10.1109/TPWRD.2004.835051

[17] Guerrero, J.M., Chandorkar, M., Lee, T.L., Loh, P.C. (2013). Advanced control architectures for intelligent microgrids-Part I: Decentralized and hierarchical control. IEEE Trans. Ind. Electron., 60(4): 1254-1262. https://doi.org/10.1109/TIE.2012.2194969

[18] Vasquez, J.C., Guerrero, J.M., Miret, J., Castilla, M., Vicuna, L.G.D. (2011). Hierarchical control of intelligent microgrids. IEEE Ind. Electron. Mag., 4(4):
23-29. https://doi.org/10.1109/MIE.2010.938720

[19] Huang, W., Lu, M., Zhang, L. (2011). Survey on microgrid control strategies. Energy Procedia, 12: 206212. https://doi.org/10.1016/j.egypro.2011.10.029

[20] Justo, J.J., Mwasilu, F., Lee, J., Jung, J.W. (2013). ACmicrogrids versus DC-microgrids with distributed energy resources: A review. Renew. Sustain. Energy Rev., 24: 387-405. https://doi.org/10.1016/j.rser.2013.03.067

[21] Shafiee, Q. (2014). Multi-Functional Distributed Secondary Control for Autonomous Microgrids. Ph.D. Thesis. Department of Energy Technology, Aalborg University.

[22] Khorsandi, A., Ashourloo, M., Mokhtari, H. (2014). A decentralized control method for a low-voltage DC microgrid. IEEE Trans. Energy Convers., 29(4): 793801. https://doi.org/10.1109/TEC.2014.2329236

[23] Moghbelli, H., Sabzi, S. (2015). Analysis and simulation of hybrid electric energy storage (HEES) systems for high power applications. 2015 ASEE Annual Conference \& Exposition, Seattle, Washington, pp. 1-13. https://doi.org/10.18260/p.23548

[24] Sabzi, S., Asadi, M., Moghbelli, H. (2017). Review, analysis and simulation of different structures for hybrid electrical energy storages. Energy Equip. Syst., 5(2): 115-129. https://doi.org/10.22059/EES.2017.25718

[25] Sabzi, S., Asadi, M., Moghbeli, H. (2019). Regenerative energy management of electric drive based on Lyapunov stability theorem. J. Mod. Power Syst. Clean Energy, 7(2): 321-328. https://doi.org/10.1007/s40565018-0497-y

[26] Mahdavi, M.S., Gharehpetian, G.B., Moghaddam, H.A. (2020). Enhanced frequency control method for microgrid-connected flywheel energy storage system. IEEE Syst. J., p. https://doi.org/10.1109/JSYST.2020.3010029

[27] Ahmed, M.A., Kang, Y.C., Kim, Y.C. (2015). Communication network architectures for smart-house with renewable energy resources. Energies, 8(8): 87168735. https://doi.org/10.3390/en8088716

[28] Loh, P.C., Li, D., Chai, Y.K., Blaabjerg, F. (2013). Autonomous control of interlinking converter with energy storage in hybrid AC-DC microgrid. IEEE Trans. Ind. $\quad$ Appl., 49(3): 1374-1382. https://doi.org/10.1109/TIA.2013.2252319

[29] Eghtedarpour, N., Farjah, E. (2014). Power control and management in a hybrid AC/DC microgrid. IEEE Trans. Smart Grid, 5(3): 1494-1505. https://doi.org/10.1109/TSG.2013.2294275

[30] Kaur, A., Kaushal, J., Basak, P. (2016). A review on microgrid central controller. Renew. Sustain. Energy Rev., 55: 338-345. https://doi.org/10.1016/j.rser.2015.10.141

[31] Olivares, D.E., Mehrizi-Sani, A., Etemadi, A.H. et al. (2014). Trends in microgrid control. IEEE Trans. Smart Grid, 5(4): 1905-1919. https://doi.org/10.1109/TSG.2013.2295514

[32] Chung, I.Y., Liu, W.X., Cartes, D.A., Collins, E.G., Moon, S.I. (2010). Control methods of inverterinterfaced distributed generators in a microgrid system. IEEE Trans. Ind. Appl., 46(3): 1078-1088. https://doi.org/10.1109/TIA.2010.2044970

[33] Nigam, S., Ajala, O., Dominguez-Garcia, A.D. (2020). A controller hardware-in-the-loop testbed: Verification 
and validation of microgrid control architectures. IEEE Electrification Mag., $\quad 8(3)$ : $\quad 92-100$. https://doi.org/10.1109/MELE.2020.3005740

[34] Armstorfer, A., Biechl, H., Rosin, A. (2019). Analysis of black start strategies for microgrids with renewable distributed generation. IECON 2019 - 45th Annual Conference of the IEEE Industrial Electronics Society, Lisbon, Portugal, pp. 2121-2125. https://doi.org/10.1109/IECON.2019.8926631

[35] Lopes, J.A.P., Moreira, C.L., Madureira, A.G. (2005) Control strategies for MicroGrids emergency operation. Int J Distrib Energy Resour, Amsterdam, Netherlands, p6. https://doi.org/10.1109/FPS.2005.204226

[36] Lopes, J.A.P., Hatziargyriou, N., Mutale, J., Djapic, P., Jenkins, N. (2007). Integrating distributed generation into electric power systems: A review of drivers, challenges and opportunities. Electr. Power Syst. Res. 77(9): 1189-1203. https://doi.org/10.1016/j.epsr.2006.08.016

[37] Chishti, F., Murshid, S., Singh, B. (2020). Natural genetics adapted control for an autonomous windbattery based microgrid. IEEE Trans. Ind. Appl., 56(6): 7156-7165. https://doi.org/10.1109/TIA.2020.3024350

[38] Ansari, S., Chandel, A., Tariq, M. (2020). A comprehensive review on power converters control and control strategies of AC/DC microgrid. IEEE Access, pp. 1-1. https://doi.org/10.1109/ACCESS.2020.3020035

[39] Lopes, J.A.P., Moreira, C.L., Madureira, A.G. (2006).
Defining control strategies for MicroGrids islanded operation. IEEE Trans. Power Syst., 21(2): 916-924. https://doi.org/10.1109/TPWRS.2006.873018

[40] Zou, Y.Y., Dong, Y., Li, S.Y., Niu, Y.G. (2019). Multitime hierarchical stochastic predictive control for energy management of an island microgrid with plug-in electric vehicles. Transm. Distrib. IET Gener., 13(10): 1794-1801. https://doi.org/10.1049/iet-gtd.2018.5332

[41] Mehrizi-Sani, A., Iravani, R. (2010). Potential-function based control of a microgrid in islanded and gridconnected modes. IEEE Trans. Power Syst., 25(4): 1883-1891. https://doi.org/10.1109/TPWRS.2010.2045773

[42] Unamuno, E., Barrena, J.A. (2015). Hybrid AC/DC microgrids-Part II: Review and classification of control strategies. Renew. Sustain. Energy Rev., 52: 1123-1134. https://doi.org/10.1016/j.rser.2015.07.186

[43] Tuladhar, A., Jin, H., Unger, T., Mauch, K. (2000). Control of parallel inverters in distributed AC power systems with consideration of line impedance effect. IEEE Trans. Ind. Appl., 36(1): 131-138. https://doi.org/10.1109/28.821807

[44] Reddy, G.V.S., Mini, V.P., Mayadevi, N., Kumar, R.H. (2020). Optimal energy sharing in smart DC microgrid cluster. 2020 IEEE International Conference on Power Electronics, Smart Grid and Renewable Energy (PESGRE2020), Cochin, India, pp. 1-6. https://doi.org/10.1109/PESGRE45664.2020.9070405 